\title{
Thermal and Mesomorphic Investigations of 1:1 Supramolecular Assemblies of 4-[(4-(n-Alkoxy)phenylimino)methyl]benzoic Acids Having Symmetrical and Un-Symmetrical Terminal Chain Lengths
}

\author{
Fowzia S. Alamro ${ }^{1}$, Hoda A. Ahmed ${ }^{2,3, * \mathbb{D}}$, Ayman M. Mostafa ${ }^{4,5,6}{ }^{\mathbb{D}}$ and Magdi M. Naoum ${ }^{2}$ \\ 1 Department of Chemistry, College of Science, Princess Nourah bint Abdulrahman University, \\ Riyadh 11671, Saudi Arabia; fsalamro@pnu.edu.sa \\ 2 Department of Chemistry, Faculty of Science, Cairo University, Cairo 12613, Egypt; \\ magdinaoum@yahoo.co.uk \\ 3 Chemistry Department, College of Sciences, Taibah University, Yanbu 30799, Saudi Arabia \\ 4 National Research Centre, Spectroscopy Department, Physics Division, El-Buhouth St., Dokki, \\ Giza 12622, Egypt; aymanmdarwish@gmail.com \\ 5 Laser Technology Unit, Centre of Excellence for Advanced Sciences, National Research Centre, Dokki, \\ Giza 12622, Egypt \\ 6 Center for Imaging and Microscopy (CIM), Zewail City of Science and Technology, October Gardens, \\ 6th of October, Giza 12578, Egypt \\ check for \\ updates \\ * Correspondence: ahoda@sci.cu.edu.eg
}

Citation: Alamro, F.S.; Ahmed, H.A.; Mostafa, A.M.; Naoum, M.M. Thermal and Mesomorphic Investigations of 1:1 Supramolecular Assemblies of 4-[(4-(n-

Alkoxy)phenylimino)methyl]benzoic Acids Having Symmetrical and Un-Symmetrical Terminal Chain Lengths. Symmetry 2021, 13, 1785. https://doi.org/10.3390/ sym13101785

Academic Editors: Rui Tamura and Sergei D. Odintsov

Received: 5 August 2021

Accepted: 18 September 2021

Published: 25 September 2021

Publisher's Note: MDPI stays neutral with regard to jurisdictional claims in published maps and institutional affiliations.

Copyright: (c) 2021 by the authors. Licensee MDPI, Basel, Switzerland. This article is an open access article distributed under the terms and conditions of the Creative Commons Attribution (CC BY) license (https:// creativecommons.org/licenses/by/ $4.0 /)$.

\begin{abstract}
Thermal and mesomorphic properties of possible 1:1 supramolecular complexes (SMCs) $\left(\mathbf{I}_{\mathbf{m}} / \mathbf{I}_{\mathbf{n}}\right)$ designed from two members of 4-[(4-(n-alkoxy)phenylimino)methyl]benzoic acid with symmetrical or un-symmetrical alkoxy terminal flexible chains (carbons of $m$ and $n=6,8$ and 16), were analyzed by differential scan-calorimetry (DSC), thermogravemetric (TG) analysis, and their mesophases identified by polarized optical microscopy (POM). The equimolecular mixtures of the two acids possess symmetrical and un-symmetrical terminal lengths. The mesomorphic properties of the binary mixtures were examined as a function of the total alkoxy chain length on both sides. Results revealed that the nematic mesophase temperature range increases as the total terminal length increases for all designed un-symmetrical mixtures. A comparison was constructed between the formed SMCs and of those of the previously prepared 4-n-alkoxyphenylazo benzoic acids as well as the 4-n-alkoxy benzoic acids, to examine the impact of mesogenic core on the mesomorphic properties. The comparison indicated that as the mesogenic portion lengthens the thermal mesophase stability exhibits higher values of phase transition temperatures; whereas, the azo and Schiff base moieties exhibited near thermal properties.
\end{abstract}

Keywords: symmetrical and un-symmetrical supramolecular-hydrogen bonding; intermolecular interactions; 4-[(4-(n-alkoxy)phenylimino)methyl]benzoic acid; thermal stability; phase transitions

\section{Introduction}

Supramolecular interactions resulted from H-bonded systems have wide attention in technological applications [1-6]. Liquid crystal (LC) materials have non-covalent interactions as well as potential applications for functional molecular shapes. The shape of the LC compounds depends on the molecular architecture [7-9] and thus has essential role for mesophase formation. One of the most important interactions in biological and chemical processes is the SMC of LCs, namely the association of molecules. Generally, the mesomorphic stability depends on the polarity and/or polarizability of the central mesogenes of the molecule. Numerous of investigated symmetrical and un-symmetrical mesomorphic $\mathrm{H}$-bonding based on the calamitic intermolecular H-bonding interactions [10-15]. Another report has studied the formation of angular complexes through intermolecular H-bond 
formation [16]. Several mesogenic derivatives containing the Schiff base as a central linking group have been reported [17-21].

On the other hand, symmetrical 4-n-alkoxyphenylimino benzoic acids [22] have been shown to possess broad ranges of mesomorphic temperatures compared to their corresponding 4-n-alkoxyphenylazo benzoic acids analogues [15] and simpler acids, 4-nalkoxybenzoic acids [14]. Other reports have also been interested on the H- bonded LC polymers [23].

The role of H-bonded interaction in the formation and stabilization of LC mesophases has been recognized in recent years [24], its role in the self-assembly of the phase has also been evaluated $[25,26]$. Thus, the intermolecular H-bond interactions have shown high potential in the thermotropic LC systems $[27,28]$. In addition, the dimerization of aromatic carboxylic acids is the first example of LC formation [29]. The behaviour of LC material is mainly dependent on the shape of the resulting SMC. Many SMCs are based on the carboxylic and pyridyl components, as proton-acceptor and proton-donor moieties, respectively [30,31].

LC materials for device displays are mostly mixtures because no single compound fulfills all the essential criteria. Therefore, the investigation of mixtures of LC components is a subject of considerable interest [32]. The most used compounds for the preparation of LC blends, via H-bonding interactions, are the benzoic acid derivatives [33]. Thus, the aim of our study is to investigate the possible formation of SMC via H-bonding interactions $\left(\mathbf{I}_{\mathrm{m}} / \mathbf{I}_{\mathbf{n}}\right)$ formed between pairs of 4-n-alkoxyazomethine benzoic acid derivatives having different terminal alkoxy chain length that varies between 6,8 and 16 carbons. The study also aims to investigate the phase behaviour of the 1:1 molar ratio binary mixtures of any two complimentary components. Furthermore, this study will evaluate the effect of the mesogenic cores as a function of total alkoxy chain length of designed complexes.

\section{Experimental}

2.1. Synthesis of 4-[(4-(n-Alkoxy)phenylimino)methyl] Benzoic Acid $\left(I_{m} \& I_{n}\right)$

Materials $\mathbf{I}_{\mathbf{m}}$ and $\mathbf{I}_{\mathbf{n}}$ were prepared according the previously reported method [22].

2.2. Formation of $S M H$-Bonded Complexes $\left(I_{m} / I_{n}\right)$

Details given in supplementary data (see Scheme 1). 


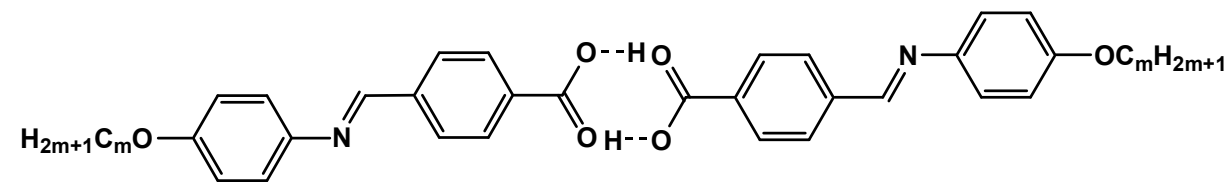

$I_{m}, m=6,8,16$

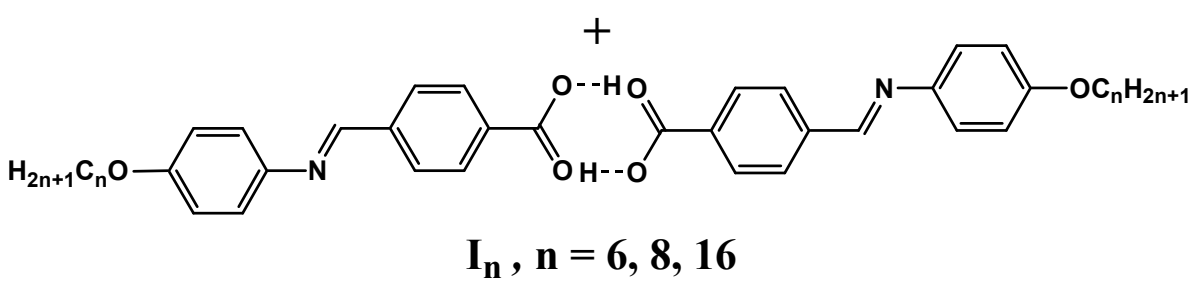

(1:1) molar ratio

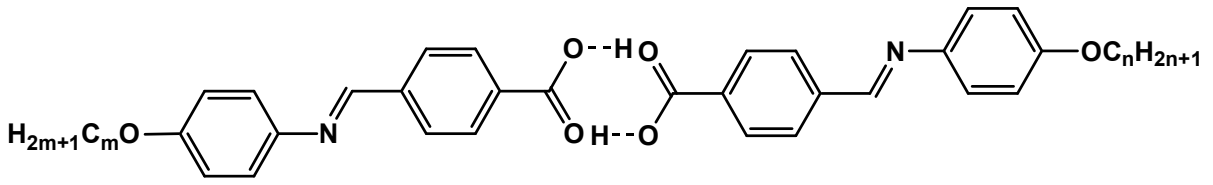

$\mathbf{I}_{\mathbf{m}} / \mathbf{I}_{\mathbf{n}}$

Scheme 1. Steps of SMCs $\left(\mathbf{I}_{\mathbf{m}} / \mathbf{I}_{\mathbf{n}}\right)$ preparations.

\section{Results and Discussion}

3.1. Effect of Total Terminal Chain Length on Mesomorphic Behaviours of 1:1 Molar Ratios of SMCs

The possible 1:1 molar binary mixtures that are formed from the three derivatives of 4-n-alkoxyphenylazomethine benzoic acids $\left(\mathbf{I}_{\mathbf{m}}\right.$ and $\left.\mathbf{I}_{\mathbf{n}}\right)$ were prepared. The mesomorphic properties of the prepared mixtures were examined via DSC and POM. The DSC thermograms of $\mathbf{I}_{\mathbf{1 6}} / \mathbf{I}_{\mathbf{1 6}}$ homologue are displayed in Figure $\mathrm{S} 3$ as a representative example and DSC curves of $\mathbf{I}_{6} / \mathbf{I}_{8}$ are depicted in Figure 1. Representative textures of the mesophases under POM are given in Figure 2. For the individual acids as well as their 1:1 molar SMC $\mathbf{I}_{\mathbf{m}} / \mathbf{I}_{\mathbf{n}}$, mesomorphic transition temperatures and their associated enthalpy are summarized in Table 1. Phase transition temperatures, as driven from DSC measurements, are displayed in Figure 3a-c, as a function of the total terminal length $(\tilde{n}=m+n)$ for $m$ and $n$ changed between 6,8 and 16 carbons, in order to investigate the effect of total terminal alkoxy chain lengths $(m+n)$ on the mesophase behaviour of SMCs. From Table 1 and Figure $3 a-c$ show that an irregular change of melting transitions as the alkoxy chain length increases for all prepared mixtures. Moreover, all SMC showed to exhibit enantiotropic mono- or di-morphic depending on the terminal lengths of chain $\mathrm{m}$ and $\mathrm{n}$. The designed supramolecular H-bonding complexes $\left(\mathbf{I}_{\mathbf{m}} / \mathbf{I}_{\mathbf{n}}\right)$ exhibit mesophases of thermal stabilities 262.8, 252.0 and $246.8^{\circ} \mathrm{C}$ upon heating for complexes $\mathbf{I}_{6} / \mathbf{I}_{8}, \mathbf{I}_{\mathbf{6}} / \mathbf{I}_{\mathbf{1 6}}$ and $\mathbf{I}_{8} / \mathbf{I}_{\mathbf{1 6}}$, respectively. Additionally, the stability of the $\mathrm{N}$ phase, $\mathrm{T}_{\mathrm{N}-\mathrm{I}}$, decreases with $\mathrm{m}$; whereas the $\mathrm{SmC}$ stability increases with $\mathrm{m}$. For $\mathrm{m}=6$ (Figure $3 \mathrm{a}$ ), all SMCs, $\mathbf{I}_{\mathbf{6}} / \mathbf{I}_{\mathbf{8}}$ and $\mathbf{I}_{\mathbf{6}} / \mathbf{I}_{\mathbf{1 6}}$ including the symmetrical dimer $\mathbf{I}_{\mathbf{6}} / \mathbf{I}_{\mathbf{6}}$ are dimorphic possessing smectic $C(\mathrm{SmC})$ and nematic $(\mathrm{N})$ mesophases. The complex $\mathbf{I}_{\mathbf{6}} / \mathbf{I}_{\mathbf{1 6}}$ shows the highest range of nematic phase nearly $77.3^{\circ} \mathrm{C}$ while the complex $\mathbf{I}_{6} / \mathbf{I}_{8}$ exhibits nematogenic range about $2.6^{\circ} \mathrm{C}$. These results are in agreement with previous reports [34] 
that is, the higher difference between the flexible wings of the mixed components, the wide $\mathrm{N}$ phase range will observed. For $\mathrm{m}=8$ (Figure $3 \mathrm{~b}$ ), all SMCs $\mathbf{I}_{8} / \mathbf{I}_{\mathbf{n}}$ have the same trend of $\mathbf{I}_{\mathbf{6}} / \mathbf{I}_{\mathbf{n}}$. Moreover, their N stabilities decrease in order to $260.2,258.0$ and $175.8^{\circ} \mathrm{C}$ for $\mathbf{I}_{8} / \mathbf{I}_{6}$, $\mathbf{I}_{8} / \mathbf{I}_{\mathbf{8}}$ and $\mathbf{I}_{\mathbf{8}} / \mathbf{I}_{\mathbf{1 6}}$, respectively. In case of the homologues $\mathbf{I}_{\mathbf{1 6}} / \mathbf{I}_{\mathbf{n}}$ (Figure $3 c$ ), the SMCs $\mathbf{I}_{16} / \mathbf{I}_{\mathbf{6}}$ and $\mathbf{I}_{\mathbf{1 6}} / \mathbf{I}_{\mathbf{8}}$ show wide nematogenic range nearly 77.3 and $71.0^{\circ} \mathrm{C}$, respectively, while the dimer $\mathbf{I}_{\mathbf{1 6}} / \mathbf{I}_{\mathbf{1 6}}$ is purely nematogenic, possessing SmC mesophase with stability temperature $239.7^{\circ} \mathrm{C}$ and range $82.7^{\circ} \mathrm{C}$. All results of mesomorphic behaviour revealed that the mixing of one derivative with the other does not disrupt arrangement of molecules within the smectic or $\mathrm{N}$ phases.

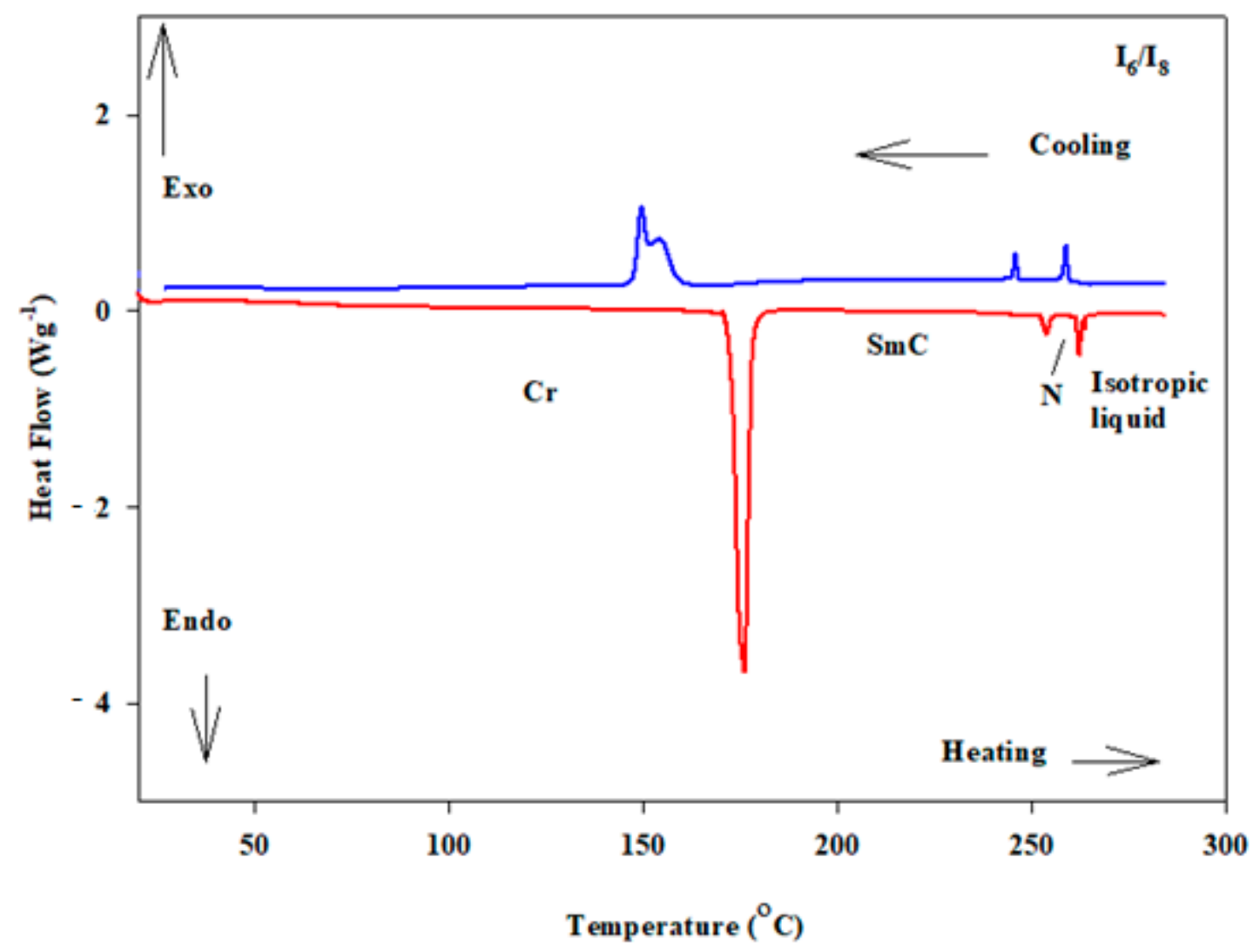

Figure 1. DSC thermograms of SMC $\mathbf{I}_{6} / \mathbf{I}_{8}$ mesured at a rate of $\pm 5{ }^{\circ} \mathrm{C} \mathrm{min}-1$ from the rounds of second heating and cooling.
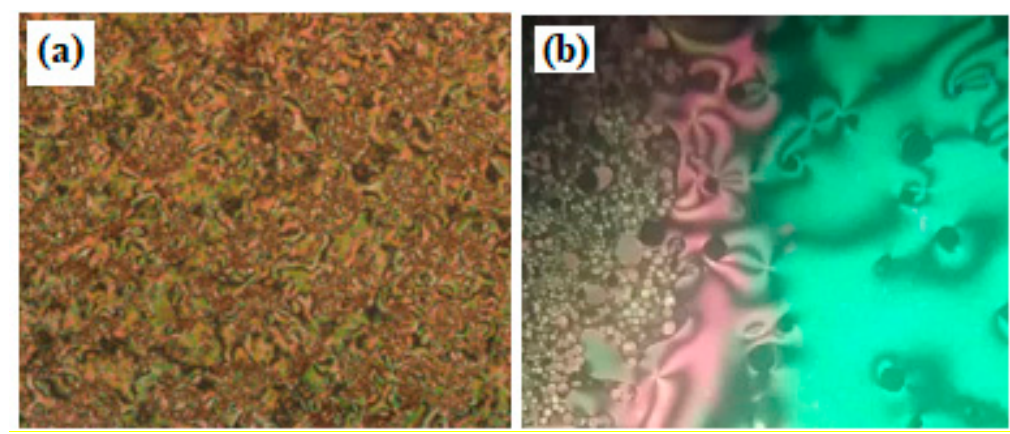

Figure 2. POM texturesof mesophases upon heating for SMC $\mathbf{I}_{\mathbf{6}} / \mathbf{I}_{\mathbf{1 6}}$ (a) SmC phase at $167.0^{\circ} \mathrm{C}$ and (b) $\mathrm{N}$ phase at $220.0^{\circ} \mathrm{C}$.

Thermal stabilities of the prepared SMCs, $\mathbf{I}_{\mathbf{m}} / \mathbf{I}_{\mathbf{n}}$, also were confirmed by thermogravimetric (TG) analysis (Figure 4). The TGA measurements revealed that, the thermal degradation takes place via one step with the maximum rate loss $\left(T_{\max }\right)$ at ca. 330, 341 and $350{ }^{\circ} \mathrm{C}$ for $\mathbf{I}_{6} / \mathbf{I}_{8}, \mathbf{I}_{6} / \mathbf{I}_{16}$ and $\mathbf{I}_{8} / \mathbf{I}_{\mathbf{1 6}}$, respectively. This shows high thermal stabilities for all formed complexes above their isotropic transitions. 
Table 1. Mesophase temperatures $\left({ }^{\circ} \mathrm{C}\right)$, enthalpy $(\mathrm{kJ} / \mathrm{mol})$ and entropy of transition for the SMCs, $\mathbf{I}_{\mathbf{m}} / \mathbf{I}_{\mathbf{n}}$.

\begin{tabular}{ccccccccccc}
\hline System & $\tilde{\mathbf{n}}$ & $\boldsymbol{T}_{\text {Cr-SmC }}$ & $\boldsymbol{\Delta} \boldsymbol{H}_{\text {Cr-SmC }}$ & $\boldsymbol{T}_{\text {SmC-I }}$ & $\boldsymbol{\Delta} \boldsymbol{H}_{\text {SmC-I }}$ & $\boldsymbol{T}_{\text {SmC-N }}$ & $\Delta \boldsymbol{H}_{\text {SmC-N }}$ & $\boldsymbol{T}_{\text {N-I }}$ & $\Delta H_{\text {N-I }}$ & $\Delta S / R$ \\
\hline $\mathrm{I}_{6} / \mathrm{I}_{6}$ & 12 & 189.0 & 55.7 & & & 257.4 & 2.7 & 265.9 & 1.8 & 0.40 \\
\hline $\mathrm{I}_{6} / \mathrm{I}_{8}$ & 14 & 175.4 & 40.1 & & 260.2 & 3.2 & 262.8 & 1.9 & 0.43 \\
\hline $\mathrm{I}_{6} / \mathrm{I}_{16}$ & 22 & 158.9 & 39.6 & & 174.7 & 2.4 & 252.0 & 1.7 & 0.39 \\
\hline $\mathrm{I}_{8} / \mathrm{I}_{8}$ & 16 & 182.0 & 49.8 & & 258.0 & 2.1 & 261.0 & 1.9 & 0.43 \\
\hline $\mathrm{I}_{8} / \mathrm{I}_{16}$ & 24 & 158.2 & 36.3 & & & 175.8 & 2.6 & 246.8 & 1.1 & 0.25 \\
\hline $\mathrm{I}_{16} / \mathrm{I}_{16}$ & 32 & 157.0 & 56.9 & 239.7 & 3.7 & & & & & 0.87 \\
\hline
\end{tabular}

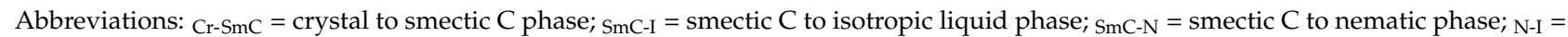
nematic to isotropic liquid phase; $\tilde{\mathbf{n}}=$ Sum of terminal chain length $\mathrm{m}+\mathrm{n}$.
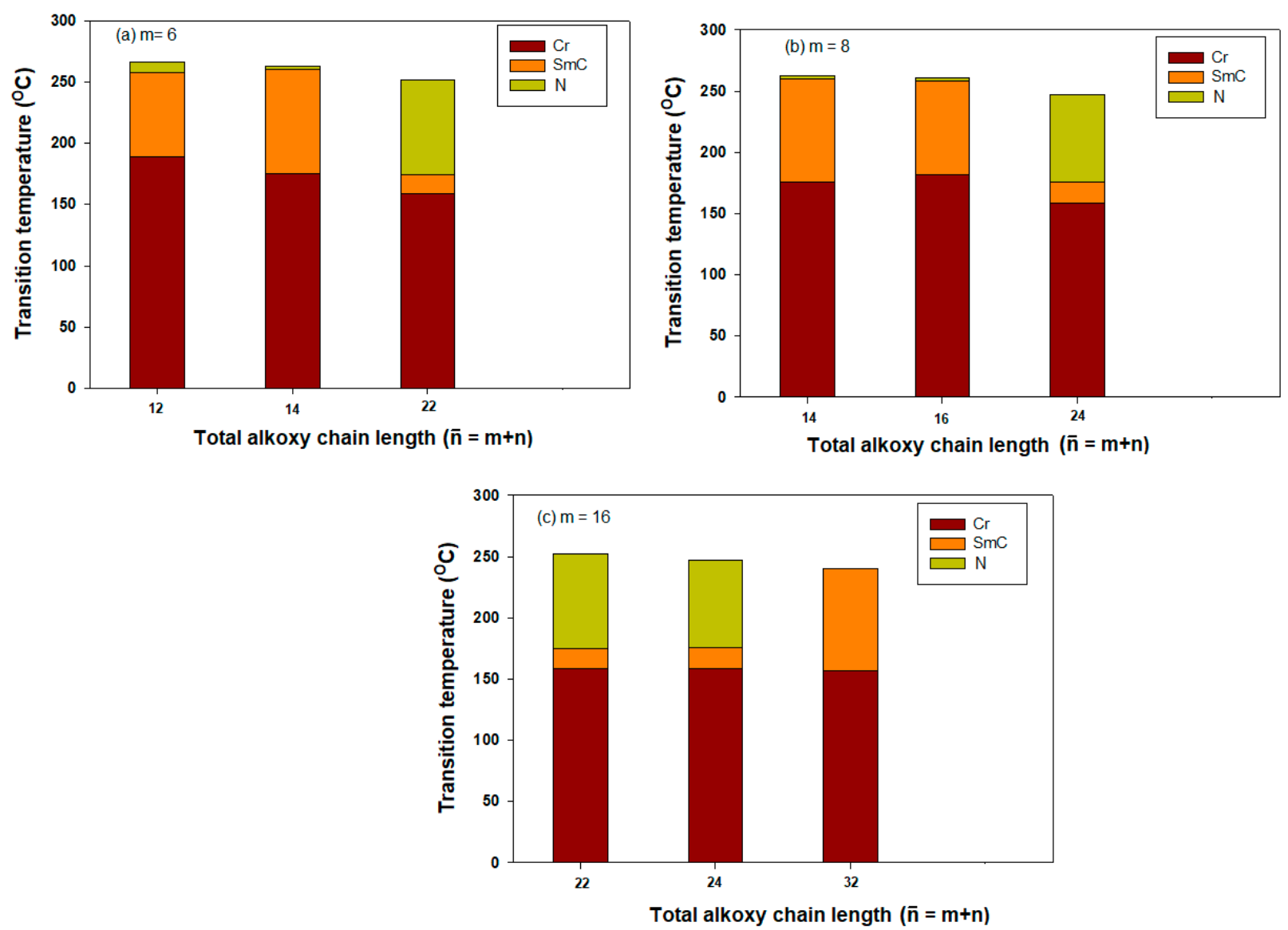

Figure 3. DSC transitions for the total length of alkoxy terminals of $1: 1$ molar SMCs, $\mathbf{I}_{\mathbf{m}} / \mathbf{I}_{\mathbf{n}}$; where $\tilde{\boldsymbol{n}}=\mathrm{m}+\mathrm{n}$.

The transition normalized entropy changes $(\Delta S / R)$ were estimated for all SMCs and tabulated in Table 1. Dependence of entropy changes with the total length of complexes are represented graphically in Figure 5. From the data in Table 2 and Figure 5, the entropy changes $(\Delta S / R)$ showed slight decrement values with the increase of the total alkoxy chain length $\tilde{n}$ up to $\tilde{n}=24$ carbons $(\Delta S / R=0.25)$ then jump to $(\Delta S / R=0.87)$ at $\tilde{n}=32$. The specific interactions between the un-like mesogens leads to the production of the smectic mesophase in un-symmetric complexes $[35,36]$. The irregular relation may be attributed to the different type of mesophases of complexes from $\tilde{n}=12$ to $\tilde{n}=24 . \Delta S / R$ of $\tilde{n}=24$ is lower than that of $\tilde{\mathrm{n}}=22$ which may be attributed to the different biaxiality of their mesogenic groups arrangement $[37,38]$. The $\mathrm{N}$ mesophases covered all of the SMC mixtures, while for $\tilde{\boldsymbol{n}}=32$ only the SmC mesophase was observed. Thus, the increase of the end-to-end associations of molecules with increasing the total length of the molecule is a result of the production of wide range of $\mathrm{N}$ phase up to $\tilde{\boldsymbol{n}}=24$. Additionally, the relatively small values 
of entropy changes observed for the binary complexes investigated are ascribed to the weak conjugative interactions within the mesogenic cores of the individual components of the complex. In another work [39], the values of $\Delta S / R$ for LC cholesteryl complexes bearing -S-S- link were found to be little which may be due to the increment of biaxiality of molecules which arising from the dihedral angle of C-S-S-C.

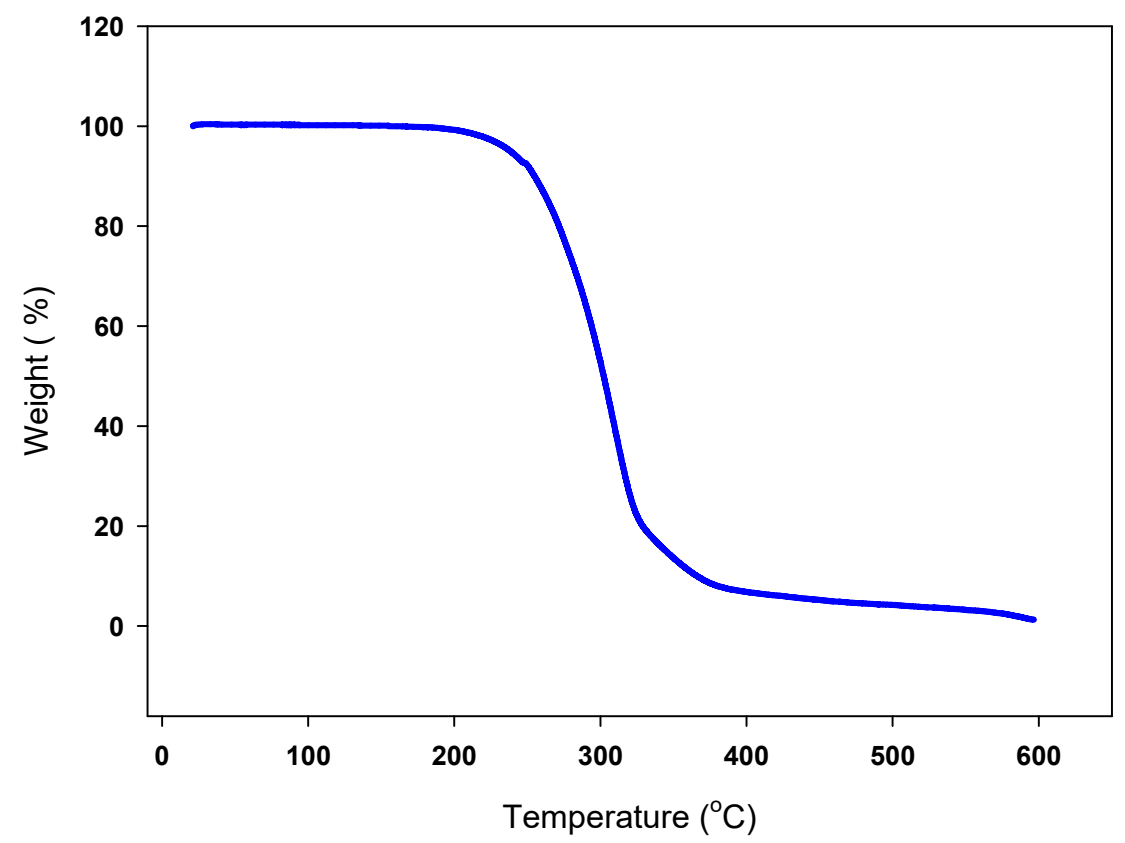

Figure 4. TGA plot of SMC $\mathbf{I}_{6} / \mathbf{I}_{8}$, as an example, recorded at heating rate of $10^{\circ} \mathrm{C} \mathrm{min}-1$ under nitrogen.

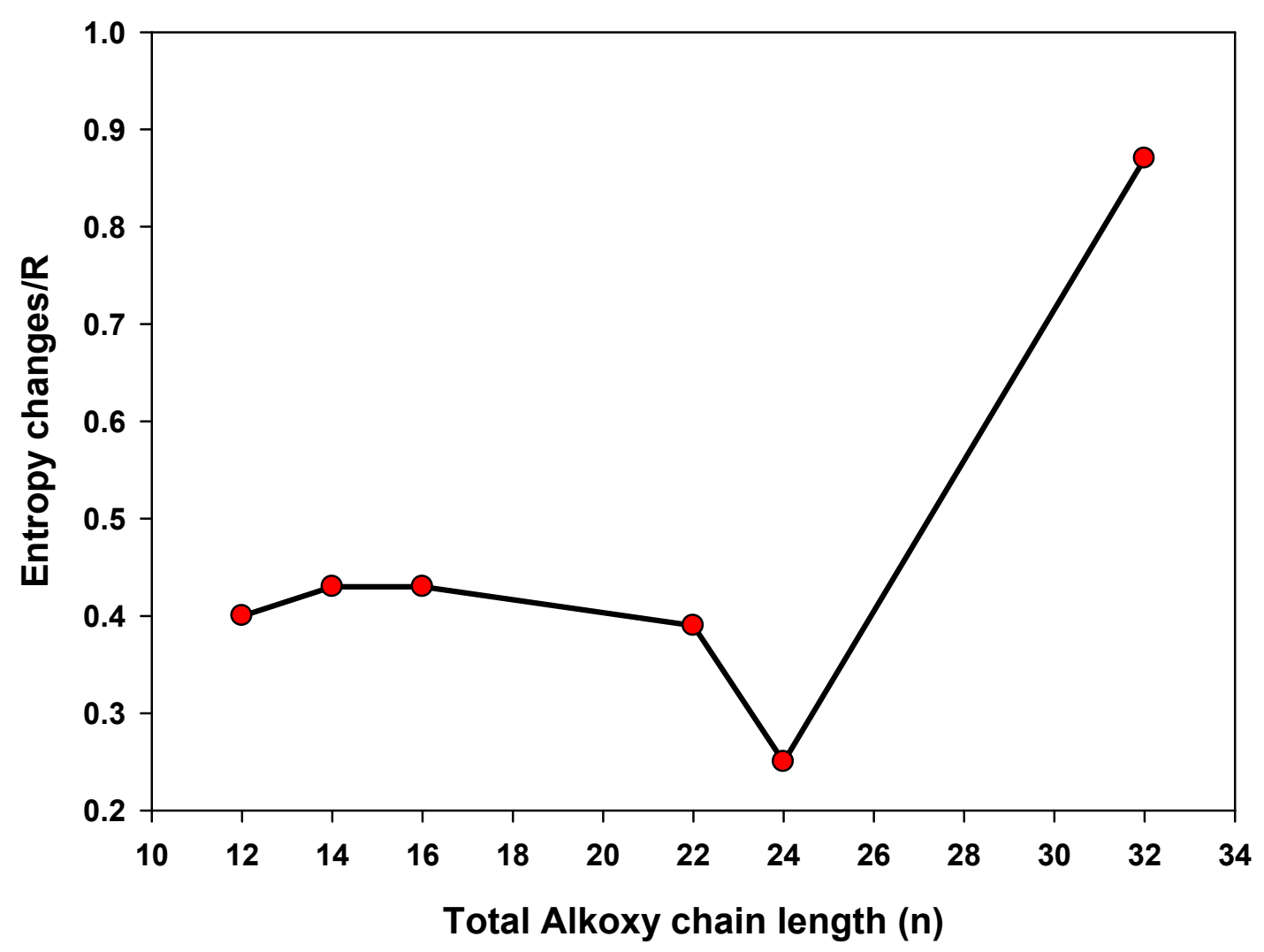

Figure 5. Dependence of the entropy changes $(\Delta S / R)$ on the total alkoxy chain length $(\tilde{n})$ of SMCs, $I_{m} / I_{n}$. 


\subsection{Effect of Mesogenic Cores on the Mesophase Stability of SMCs}

The terminal flexible length and the mesogenic portion of components have effective roles on the thermal stability and the type of the formed mesophase. It had been documented that the difference polarity between $\mathrm{H}$-acceptor and $\mathrm{H}$-donors impacts the strength of H-bonding and lengthen the molecular anisotropy as well as broaden of the mesomorphic range [15]. On the other side, the polarity of either components of the mixture is not impacted by the length of the ends group. In order to evaluate the effect of different mesogenic cores on the mesomorphic stability $\left(T_{C}\right)$, comparisons were made between the present SMCs, $\mathbf{I}_{\mathbf{m}} / \mathbf{I}_{\mathbf{n}}$, and the our previously investigated 4-n-alkoxy phenylazo benzoic acids complexes, $\mathbf{I I}_{\mathrm{m}} / \mathbf{I I}_{\mathbf{n}}$ [15] and simple 4-alkoxybenzoic acids mixtures $\left(\mathbf{I I I}_{\mathbf{m}} / \mathbf{I I I}_{\mathbf{n}}\right)$ [14] Thermal stabilities $\left(T_{C}\right)$ data for all SMCs are collected in Table 2 and displayed graphically in Figure 6. The comparison was established between their mesomorphic stabilities $\left(T_{C}\right)$ as a function of total alkoxy chain length ( $\tilde{n})$. The comparison of $\mathbf{I}_{\mathbf{m}} / \mathbf{I}_{\mathbf{n}}$ with the simplest complexes III $_{\mathbf{m}} / \mathrm{III}_{\mathbf{n}}$ revealed that, the incorporation of extra Schiff base linkage has led to increment the mesogenic core length and consequently, the mesomorphic thermal stability of present investigated mixtures show higher values of transition temperatures.

Another comparison was established between the phase stability of Schiff base complexes $\left(\mathbf{I}_{\mathbf{m}} / \mathbf{I}_{\mathbf{n}}\right)$ and their corresponding phenylazo benzoic acids mixtures $\left(\mathbf{I I}_{\mathbf{m}} / \mathbf{I I}_{\mathbf{n}}\right)$ and the data indicated that, both series having near thermal stabilities after replacing the $-\mathrm{N}=\mathrm{N}$ -

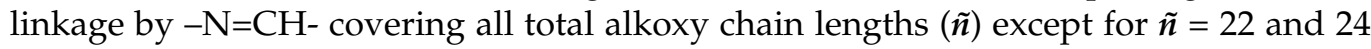
the azomethine complexes $\left(\mathbf{I}_{\mathbf{m}} / \mathbf{I}_{\mathbf{n}}\right)$ which showed to possess higher thermal mesophase stabilities than those of the azo based mixtures $\left(\mathbf{I I}_{\mathbf{m}} / \mathbf{I I}_{\mathbf{n}}\right)$. These results indicate that the Schiff base and azo moieties exhibit nearly the same polarizability values. On the other hand, the previous study of the phenylazo mixtures [15] revealed that, as the mesogenic core length is increased the phase stabilities of smectic and $\mathrm{N}$ phases are increased. In addition, the mesomorphic range of SmC formed has shown to also be increased upon the incorporation of the phenylazo unit. While in the present investigated Schiff base mixtures $\left(\mathbf{I}_{\mathbf{m}} / \mathbf{I}_{\mathbf{n}}\right)$ the stability of SmC slightly decreases as the length of tails become increases which may be attributed to participation of other geometrical parameters that affects the molecular arrangements. Moreover, their SmC and N ranges have shown to change in irregular manners.<smiles>CCCCCCCCCCOc1ccc(N=Nc2ccc(C(=O)OC)cc2)cc1</smiles><smiles>CCOc1ccc(C(=O)OCOC(=O)c2ccc(OCC)cc2)cc1</smiles>

\section{III $_{\mathbf{m}} / \mathbf{I I I}_{\mathbf{n}}$}


Table 2. Thermal mesophase stabilities of systems $I_{m} / I_{n}, I_{m} / I_{n}$ and $\mathbf{I I I}_{m} / \mathbf{I I I}_{n}$.

\begin{tabular}{ccccccc}
\hline$\tilde{\mathbf{n}}$ & $\begin{array}{c}\text { System } \\
-\mathbf{N}=\mathbf{C H}-\end{array}$ & $\mathbf{T}_{\mathbf{C}}$ & $\begin{array}{l}\text { System } \\
-\mathbf{N}=\mathbf{N}-\end{array}$ & $\mathbf{T}_{\mathbf{C}}$ & $\begin{array}{c}\text { System } \\
-\end{array}$ & $\mathbf{T}_{\mathbf{C}}$ \\
\hline 12 & $\mathrm{I}_{6} / \mathrm{I}_{6}$ & 265.9 & $\mathrm{II}_{6} / \mathrm{II}_{6}$ & 264.0 & $\mathrm{III}_{6} / \mathrm{III}_{6}$ & 158.0 \\
\hline 14 & $\mathrm{I}_{6} / \mathrm{I}_{8}$ & 262.8 & $\mathrm{II}_{6} / \mathrm{II}_{8}$ & 266.0 & $\mathrm{III}_{6} / \mathrm{III}_{8}$ & 151.6 \\
\hline 16 & $\mathrm{I}_{8} / \mathrm{I}_{8}$ & 261.0 & $\mathrm{II}_{8} / \mathrm{II}_{8}$ & 260.0 & $\mathrm{III}_{8} / \mathrm{III}_{8}$ & 147.0 \\
\hline 22 & $\mathrm{I}_{6} / \mathrm{I}_{16}$ & 252.0 & $\mathrm{II}_{6} / \mathrm{II}_{16}$ & 241.0 & $\mathrm{III}_{6} / \mathrm{III}_{16}$ & 130.2 \\
\hline 24 & $\mathrm{I}_{8} / \mathrm{I}_{16}$ & 246.8 & $\mathrm{II}_{8} / \mathrm{II}_{16}$ & 242.9 & $\mathrm{III}_{8} / \mathrm{III}_{16}$ & 133.0 \\
\hline 32 & $\mathrm{I}_{16} / \mathrm{I}_{16}$ & 239.7 & $\mathrm{II}_{16} / \mathrm{II}_{16}$ & 240.0 & $\mathrm{III}_{16} / \mathrm{III}_{16}$ & 132.5 \\
\hline
\end{tabular}

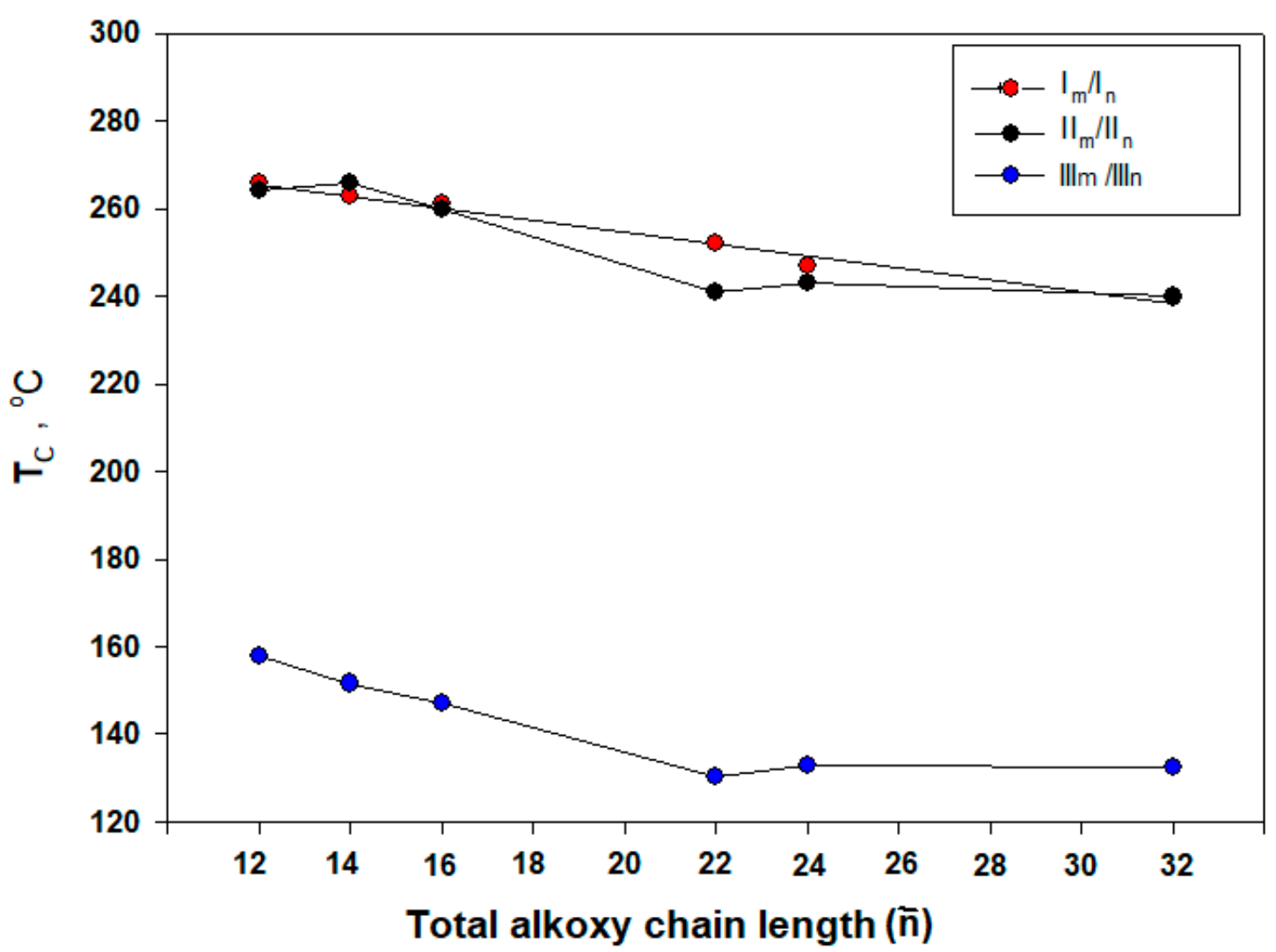

Figure 6. Dependence of thermal mesophase stabilities of the complexes $I_{m} / I_{n}, I_{m} / I_{n}$ and $\mathbf{I I I}_{m} / \mathbf{I I I}_{n}$ on the total terminal alkoxy chains length.

\section{Conclusions}

New binary series of 1:1 molar SMC of 4-[(4-(n-alkoxy)phenylimino)methyl]benzoic acids, with symmetrical and un-symmetrical proportionated terminal alkoxy chain lengths, were prepared and investigated thermally and mesomorphically. The results revealed that all mixtures are dimorphic with enantiotropic SmC and $\mathrm{N}$ phases. With a Lengthening of the total alkoxy chain, in the two wings of the 1:1 SMCs, the $\mathrm{N}$ phase temperature range increases. In addition to all designed SMCs show high thermal stability above their isotropic temperatures. The comparison between the present SMCs $\left(\mathbf{I}_{\mathbf{m}} / \mathbf{I}_{\mathbf{n}}\right)$ and each of the previously investigated 4-n-alkoxyphenylazo benzoic acids complexes $\left(\mathbf{I I}_{\mathbf{m}} / \mathbf{I I}_{\mathbf{n}}\right)$ and its simpler analogues $\left(\mathrm{III}_{\mathbf{m}} / \mathrm{III}_{\mathbf{n}}\right)$ revealed that increasing the mesogenic core length is associated with a considerable conjugative interactions between the terminals of each of the two components in binary mixtures that show parallel phase behaviour as a function of the total alkoxy chain lengths. Moreover, the effect of the alkoxy chain length that is 
attached to the ring of the azomethine moiety is found to be more effective compared with those connected to benzoate unit which is nearly similar to the phenylazo analogues.

Supplementary Materials: The following are available at https://www.mdpi.com/article/10.3390/ sym13101785/s1. The synthetic and characterization details of investigated compounds as well as Figures S1-S4.

Author Contributions: Formal analysis, A.M.M., H.A.A., and F.S.A.; Funding acquisition, F.S.A. and H.A.A.; Methodology, F.S.A. and H.A.A.; Project administration, F.S.A.; Resources and Software, M.M.N. and H.A.A.; Writing-original draft, H.A.A., F.S.A., A.M.M. and M.M.N.; Writing-review and editing, H.A.A., A.M.M. and M.M.N. All authors have read and agreed to the published version of the manuscript.

Funding: This research was funded by the Deanship of Scientific Research at Princess Nourah bint Abdulrahman University through the Fast-track Research Funding Program.

Institutional Review Board Statement: Not applicable.

Informed Consent Statement: Not applicable.

Data Availability Statement: The data presented in this study are available on request from the corresponding author.

Acknowledgments: The authors acknowledge the Deanship of Scientific Research at Princess Nourah bint Abdulrahman University through the Fast-track Research Funding Program.

Conflicts of Interest: The authors declare no conflict of interest.

\section{References}

1. Demus, D.; Goodby, J.W.; Gray, G.W.; Spiess, H.W.; Vill, V. Handbook of Liquid Crystals, Volume 2A: Low Molecular Weight Liquid Crystals I: Calamitic Liquid Crystals; John Wiley \& Sons: Hoboken, NJ, USA, 2011.

2. Kato, T.; Fréchet, J.M.J. Hydrogen bonding and the self-assembly of supramolecular liquid-crystalline materials. Macromol. Symp. 1995, 98, 311-326. [CrossRef]

3. Kato, T.; Hirota, N.; Fujishima, A.; Fréchet, J.M. Supramolecular hydrogen-bonded liquid-crystalline polymer complexes. Design of side-chain polymers and a host-guest system by noncovalent interaction. J. Polym. Sci. Part A Polym. Chem. 1996, 34, 57-62. [CrossRef]

4. Lehn, J.-M. Supramolecular chemistry-Molecular information and the design of supramolecular materials. Makromol. Chemie. Macromol. Symp. 1993, 69, 1-17. [CrossRef]

5. Paleos, C.M.; Tsiourvas, D. Thermotropic Liquid Crystals Formed by Intermolecular Hydrogen Bonding Interactions. Angew. Chem. Int. Ed. 1995, 34, 1696-1711. [CrossRef]

6. Gomha, S.M.; Ahmed, H.A.; Shaban, M.; Abolibda, T.Z.; Alharbi, K.A.; Alalawy, H.H. New nematogenic conical-shaped supramolecular H-bonded complexes for solar energy investigations. Sci. Rep. 2021, 11, 17622. [CrossRef] [PubMed]

7. Xiao, S.; Zou, Y.; Wu, J.; Zhou, Y.; Yi, T.; Li, F.; Huang, C. Hydrogen bonding assisted switchable fluorescence in self-assembled complexes containing diarylethene: Controllable fluorescent emission in the solid state. J. Mater. Chem. 2007, 17, 2483-2489. [CrossRef]

8. Kohmoto, S.; Someya, Y.; Kishikawa, K. Liquid crystalline molecules with hydrogen-bonding networks in the direction of molecular short axes. Liq. Cryst. 2010, 37, 209-216. [CrossRef]

9. Alamro, F.S.; Ahmed, H.A.; Naoum, M.M.; Mostafa, A.M.; Alserehi, A.A. Induced Smectic Phases from Supramolecular H-Bonded Complexes Based on Non-Mesomorphic Components. Crystals 2021, 11, 940. [CrossRef]

10. Naoum, M.M.; Fahmi, A.A.; Alaasar, M.A.; Salem, R.A. Supramolecular liquid crystals in binary and ternary systems. Thermochim. Acta 2011, 517, 63-73. [CrossRef]

11. Naoum, M.M.; Fahmi, A.A.; Mohammady, S.Z.; Abaza, A.H. Effect of lateral substitution on supramolecular liquid crystal associates induced by hydrogen-bonding interactions between $4-\left(4^{\prime}\right.$-pyridylazo-3-methylphenyl)- $4^{\prime \prime}$-alkoxy benzoates and 4-substituted benzoic acids. Liq. Cryst. 2010, 37, 475-486. [CrossRef]

12. Ahmed, H.A.; Hagar, M.; Alaasar, M.; Naoum, M. Wide nematic phases induced by hydrogen-bonding. Liq. Cryst. 2019, 46, 550-559. [CrossRef]

13. Ahmed, H.A.; Hagar, M.; Aljuhani, A. Mesophase behavior of new linear supramolecular hydrogen-bonding complexes. RSC Adv. 2018, 8, 34937-34946. [CrossRef]

14. Ahmed, H.; Naoum, M. Mesophase behavior of binary and ternary mixtures of benzoic acids bearing terminal substituents of different polarity and chain-lengths. Thermochim. Acta 2014, 575, 122-128. [CrossRef]

15. Ahmed, H.; Naoum, M.; Saad, G. Mesophase behaviour of 1:1 mixtures of 4-n-alkoxyphenylazo benzoic acids bearing terminal alkoxy groups of different chain lengths. Liq. Cryst. 2016, 43, 1259-1267. [CrossRef] 
16. Ahmed, H.; Naoum, M. Mesophase behaviour of azobenzene-based angular supramolecular hydrogen-bonded liquid crystals. Liq. Cryst. 2016, 43, 222-234. [CrossRef]

17. Arakawa, Y.; Sasaki, Y.; Tsuji, H. Supramolecular hydrogen-bonded liquid crystals based on 4-n-alkylthiobenzoic acids and 4,4'-bipyridine: Their mesomorphic behavior with comparative study including alkyl and alkoxy counterparts. J. Mol. Liq. 2019, 280, 153-159. [CrossRef]

18. Vasanthi, T.; Subhasri, P.; Jayaprakasam, R.; Vijayakumar, V.N. Experimental and computational studies on induced thermochromic effect and re-entrant smectic phase in linear double hydrogen-bonded binary liquid crystal mixtures. Phase Transit. 2019, 92, 229-248. [CrossRef]

19. Kishor, M.H.; Mohan, M.M. Investigations on smectic $X^{*}$ and re-entrant smectic $C^{*}$ orderings in hydrogen bonded ferroelectric liquid crystals. J. Mol. Liq. 2019, 273, 504-524. [CrossRef]

20. El-Atawy, M.A.; Naoum, M.M.; Al-Zahrani, S.A.; Ahmed, H.A. New Nitro-Laterally Substituted Azomethine Derivatives; Synthesis, Mesomorphic and Computational Characterizations. Molecules 2021, 26, 1927. [CrossRef]

21. Al-Mutabagani, L.; Alshabanah, L.; Ahmed, H.; Alalawy, H.; Al Alwani, M. Synthesis, Mesomorphic and Computational Characterizations of Nematogenic Schiff Base Derivatives in Pure and Mixed State. Molecules 2021, 26, 2038. [CrossRef] [PubMed]

22. Weissflog, W.; Lischka, C.; Diele, S.; Pelzl, G.; Wirth, I.; Grande, S.; Kresse, H.; Schmalfuss, H.; Hartung, H.; Stettler, A. BananaShaped or Rod-Like Mesogens? Molecular Structure, Crystal Structure and Mesophase Behaviour of 4,6-Dichloro-1,3-Phenylene Bis[4-(4-n-Subst.-Phenyliminomethyl) Benzoates]. Mol. Cryst. Liq. Cryst. Sci. Technol. Sect. A. Mol. Cryst. Liq. Cryst. 1999, 333, 203-235. [CrossRef]

23. Martinez-Felipe, A.; Lu, Z.; Henderson, P.A.; Picken, S.J.; Norder, B.; Imrie, C.T.; Ribes-Greus, A. Synthesis and characterisation of side chain liquid crystal copolymers containing sulfonic acid groups. Polymers 2012, 53, 2604-2612. [CrossRef]

24. Alaasar, M.; Tschierske, C.; Prehm, M. Hydrogen-bonded supramolecular complexes formed between isophthalic acid and pyridine-based derivatives. Liq. Cryst. 2011, 38, 925-934. [CrossRef]

25. Lehn, J.M. Supramolecular chemistry-scope and prespectives, molecules, supermolecules and molecular devices. Angew. Chem. Int. Ed. Engl. 1988, 27, 89-112. [CrossRef]

26. Constantinos, M.P.; Dimitris, T. Supramolecular hydrogen-bonded liquid crystals. Liq. Cryst. 2001, 28, 1127-1161.

27. Thote, A.J.; Gupta, R.B. Hydrogen-Bonding Effects in Liquid Crystals for Application to LCDs. Ind. Eng. Chem. Res. 2003, 42, 1129-1136. [CrossRef]

28. Gabard, J.; Lehn, J.-M.; Stibor, I. Macroscopic expression of molecular recognition. Supramolecular liquid crystalline phases induced by association of complementary heterocyclic components. J. Chem. Soc., Chem. Commun. 1989, 24, 1868-1870. [CrossRef]

29. Bradfield, A.E.; Jones, B.J. Two apparent cases of liquid crystal formation. J. Chem. Soc. 1929, 1, 2660-2661. [CrossRef]

30. Sastry, S.S.; Sarada, K.L.; Mallika, K.; Rao, C.N.; Lakhminarayana, S.; Tiong, H.S. Eigen value analysis studies on hydrogen-bonded mesogens. Liq. Cryst. 2014, 41, 1483-1494. [CrossRef]

31. Miranda, M.D.; Chavez, F.V.; Maria, T.M.; Eusébio, M.E.S.; Sebastião, P.; Silva, M. Self-assembled liquid crystals by hydrogen bonding between bipyridyl and alkylbenzoic acids: Solvent-free synthesis by mechanochemistry. Liq. Cryst. 2014, 41, 1743-1751. [CrossRef]

32. Sarkar, S.D.; Choudhury, B. Study of binary mixtures of two liquid crystallinesamples showing induced smectic phase. Assam Univ. J. Sci. Technol. Phys. Sci. Technol. 2010, 5, 167-168.

33. Lohar, J.M. A study of mixed liquid crystal formation in mix-ture of p-methoxy and p-ethoxy benzoic acids. J. Phys. 1975, 36, 399-401.

34. Gray, G.W. Molecular Structure and the Properties of Liquid Crystals; Academic Press: London, UK, 1962; pp. 239-298.

35. Yeap, G.-Y.; Hng, T.-C.; Yeap, S.-Y.; Górecka, E.; Ito, M.M.; Ueno, K.; Okamoto, M.; Mahmood, W.; Imrie, C. Why do nonsymmetric dimers intercalate? The synthesis and characterization of the $\alpha$-(4-benzylidene-substituted-aniline- $4^{\prime}$-oxy)- $\omega$-(2-methylbutyl- $4^{\prime}-$ (4" ${ }^{\prime \prime}$-phenyl) benzoateoxy)alkanes. Liq. Cryst. 2009, 36, 1431-1441. [CrossRef]

36. Attard, G.; Date, R.; Imrie, C.T.; Luckhurst, G.R.; Roskilly, S.J.; Seddon, J.; Taylor, L. Non-symmetric dimeric liquid crystals the preparation and properties of the $\alpha$-(4-cyanobiphenyl-4'-yloxy)- $\omega-\left(4-n-a l k y l a n i l i n e b e n z y l i d e n e-4^{\prime}\right.$-oxy) alkanes. Liq. Cryst. 1994, 16, 529-581. [CrossRef]

37. Lizu, M.; Lutfor, M.R.; Surugau, N.L.; How, S.-E.; Arshad, S.E. Synthesis and Characterization of Ethyl Cellulose-Based Liquid Crystals Containing Azobenzene Chromophores. Mol. Cryst. Liq. Cryst. 2010, 528, 64-73. [CrossRef]

38. Date, R.W.; Imrie, C.T.; Luckhurst, G.R.; Seddon, J. Smectogenic dimeric liquid crystals. The preparation and properties of the $\alpha, \omega$-bis(4-n-alkylanilinebenzylidine-4'-oxy)alkanes. Liq. Cryst. 1992, 12, 203-238. [CrossRef]

39. Lee, H.-C.; Lu, Z.; Henderson, P.A.; Achard, M.F.; Mahmood, W.A.K.; Yeap, G.Y.; Imrie, C.T. Cholesteryl-based liquid crystal dimers containing a sulfur-sulfur link in the flexible spacer. Liq. Cryst. 2012, 39, 259-268. [CrossRef] 